\title{
A Study of Information Technology Governance Initiatives On Organizational Performance
}

\author{
Bentolhoda Abdollahbeigi ${ }^{1 *}$, FARHang SAlehi ${ }^{2}$ \\ ${ }^{1}$ Research Department, APH Rosha, IRAN \\ ${ }^{2}$ Research Department, APH Rosha, IRAN
}

\begin{abstract}
The paper aims to clarify the relationship between Information technology governance initiatives on effective information technology governance (ITG) and organizational performance. A quantitative study through a questionnaire survey has done for this research. Data was obtained from seven states in Malaysia, within the manufacturing sector. Structural equation modelling (SEM) was used in this study to analyze the measurement and structural models simultaneously to test the role effect of ITG between information technology governance initiatives and organizational performance. The paper provides empirical insights about the relations between information technology governance initiative and the efficacy of ITG and organizational performance. The results and findings of the research can have beneficial to supporting manufacturing organizations in their efforts towards carrying out improvement activities.
\end{abstract}

Key-Words: - IT Governance Initiative, Effective IT governance, Organization Performance, Manufacturing Company

Received: September 26, 2020. Revised: February 5, 2021. Accepted: April 10, 2021. Published: April 26, 2021.

\section{Introduction}

At the beginning of the 21st-century importance of IT was not known well by many organizations; the IT department's job was limited to installing, maintaining, and updating software and hardware for the organization. ITG has grown in its significance in the past years spurred by the different IT development trends, Nowadays most of the organizations are using a system for the different department which those systems are highly IT related. But in many companies, there is not enough knowledge that how important is IT in their Organization. Due to the fast-paced development globally and locally in the IT industry, there has been an increased interest in the area of ITG in Malaysia. This study aims to examine the relations of ITG initiatives with the efficacy of ITG and organization performance. The ITG research continues to get more attention in Malaysia [1]. The development of ITG remains a challenge to organizations, creating and updating businesses using IT have highly considered by the implementation of effective ITG; Effective ITG guarantees the alignment between business goals and IT infrastructure in organizations [2]. In contrast, companies without effective ITG will suffer from inaccuracy of information quality, the inefficiency of operating costs, inaccurate estimation of IT project costs, failure in competitiveness, the inefficient performance of IT divisions or the whole organization; these problems will reduce the performance of the organization [3] .

Recently, information technology governance has become a critical issue for many companies in various industries; this is even more important for enterprises due to the more complex business processes, more specified tasks, and departments. Many companies suffer from extra costs of IT and other processes due to failure inefficient alignment between IT and business strategies which in turn, leads to low performance of the company. To overcome this problem, organizations need to have an effective ITG to make IT resources management more valuable, less substitutable, rarer, and less imitable. To do so, firms need to use IT governance initiatives to increase their effectiveness [2].

[4] Reviews the existing literature in a thorough manner to build evidence that supports that IT governance has a causal relationship with 
organization performance. To understand the effect of IT governance initiatives on effective IT governance, and organizational performance, it is imperative that a rigorous study be conducted to determine how effective IT governance affect organizational performance.

According to [5] IT governance initiatives can affect the governance performance and, consequently, the organizational performance; he refers to identify the direct and indirect benefits provided by the IT governance mechanisms most commonly adopted by firms showing the effects of these mechanisms on business. It is important to investigate how IT governance initiatives can affect effective IT governance and organizational performance. However, there is a lack of studies to make a clear perspective of how IT governance initiatives can affect effective IT governance and how it can lead to successful organizational performance. Realizing the great potential of IT governance initiatives and effective IT governance despite its numerous hurdles, it is imperative to determine factors that, in the end, will be able to help the Malaysian manufacturing industries to engage better with IT governance and help them to increase their organizational performance.

There are several types of research in the area of IT governance and its relationship with organizational performance $[2,6,7]$. However, there is a lack of studies that examine the role of IT governance initiatives as well as the mediating influence of IT governance effectiveness on organizational performance in an integrated form. This is the focal point of this study. In addition, there are limited studies about IT governance in Malaysia and a seeming lack of awareness studies on IT governance from the Malaysian perspective $[2,4,5]$.

ITG is vital to ensure successful IT intervention in organizations. Research has shown that proper ITG leads to good IT implementation and thus possibly leading to better organizational performance. Although it is generally accepted that ITG leads to good IT implementation, only limited research has dived into this area. Specifically, there is room for research to examine if ITG initiatives have an impact on the effectiveness of ITG. Besides the role of effective ITG as a mediator between ITG initiatives and Organizational performance has not been examined.

Although the importance of IT governance has been known by organizations, the effect of IT governance initiative and effective IT governance on organization Performance in Malaysian manufacturing companies are still not well established.

The purpose of this research is a combination of exploratory and descriptive research that aims to investigate the determinants of Malaysian IT governance and its influence on organizational performance. This research plans to use a survey method to understand the relationships between all proposed variables. Finally, this study intends to the connection between IT governance initiative, effective IT governance, and organizational performance in the manufacturing industries in Malaysia.

The rest of this paper is structured as follows. The next section provides a systematic review of literature on IT Governance Initiative, Effective IT governance, and Organization Performance, followed by an explanation of the research methodology. Subsequently, the findings derived from the survey questioners were presented and discussed. The last section provides the overall conclusion, contributions and limitations, and future research.

\subsection{Overview of literature on IT Governance Initiative}

Previous studies included limited factors as IT governance initiatives: IT strategy committee, IT steering committee, the involvement of senior management in IT, and corporate communication system $^{2}$. Because of the increasing importance of IT in business strategies and core operating processes, the board of directors must involve in securing effective IT governance [8]. IT steering committee is a high-level executive team, including representatives from different departments or divisions within the firm with the main purpose of connecting its business strategy and IT strategy [8]. The involvement of senior management is another factor that appears to play important role in efficient IS planning and consequently effective IT governance. Effective IT governance needs close interaction between IT and business to maintain better understanding between them and, as a result, establishing good collaboration and participation in the organization.

\subsubsection{Involvement of Senior Management in IT}

[2], reveal that the involvement of senior management affects the level of an effective ITG in a positively significant manner. Overall, the support from the management is an essential component of adopting and implementing IT outsourcing for firms. IT Outsourcing strategies are stuck in the 
initial idea phase when there is no one championing the course. The support of the senior management affects the success of initiatives on new systems through the promotion of employee empowerment; through the facilitation of employee engagement; through the promotion of a culture shift and enhanced commitment by the employees of an organization; through the act of giving rewards and incentives that influence employees' behaviors; through the offer of training and the improvement of communications across departments and motivating teamwork in the organizations. In this research, the measurement factors for the involvement of senior management are the IT strategy committee and IT steering committee.

\subsubsection{Corporate Communication Systems}

An effective ITG venture must include a close association between the divisions of IT and business for greater understanding between the two hence getting better participation and teamwork in a firm [9]. A sound communication mechanism will allow the two entities (IT and business) to enhance the other party's knowledge of the significance of having each other's views on the advantages from IT [8] It is also important for ITG to have a sound communication system since it aims to inform the entire firm regarding the processes and decisions are undertaken by the ITG and to motivate favourable behaviors in the firm [9]. Communication is normally considered to be vital to a client firm and a vendor to provide proper information. Nevertheless, the contrary is also true as the client reduces its level of control in services and functions during outsourced activities.

\subsubsection{Organizational Demographics}

Organization demographics will evaluate how an organization uses its size and age as a resource to improve its performance in IT and also to have a competitive advantage [10]. The demographics of an organization are described based on the organization's size and age. Organization demographics as the determinant of IT Governance Initiatives is about how an organization uses the advantage of its age and size as an internal resource to have more effective ITG [2]. Based on the organizations in Austria points out that for bigger organizations, the success rate of the ERP system goes up when the level of commitment of the top management to ITG increases. The usage of IT in large firms will be more successful than for smaller firms as IT helps simplify the act of bureaucratic complexity according to the bigger firm size. Firm size is also a determinant that can be examined for bigger firms with enough resources but with poor motivation to use IT more effectively compared to the smaller firms [11]. Many organizations at present find it challenging because IT is changing rapidly and these changes can only be used and properly adapted by the younger organizations [12].

\subsubsection{Organizational Culture}

Successful companies have distinct organizational culture compared to the not so successful companies as the established work cultures are articulated clearly along with shared values and norms based on the organization's functions. An organization's work environment, its objectives, and vision are represented by the values, attitudes, beliefs, and behaviours, also organizational culture goes beyond the fundamental assumptions and beliefs shared by an organization's members that function unconsciously. Organizational culture is the underlying beliefs, values, as well as principles that are foundational in a company's management system and the practices and behaviours of the management that exemplify and reinforce the fundamental principles. This research considered the four characteristics of the organizational culture in Denison's model.

\subsubsection{External Environment Characteristics}

Environmental uncertainty refers to how an organization responds to the external environment using its resources as an internal factor. According to, environmental uncertainty is a measurement of the amount of stability, complexity, dispersion, or otherwise found in an environment. The research by [13], [14] shows that environmental uncertainties support the success of perceived IT and the stability and predictability of industry sectors, government, and effective economic impact; although no empirical testing was reported in the study. The three variables widely utilized in this study are environmental heterogeneity and the dynamism of the environment.

\subsubsection{IT Function Characteristics}

The characteristics of the IT function reveal determinants such as the IT budget size, the IT division size, as well as the maturity of the IT function. The IT budget and the role of IT in the financial planning; For the cost-cutting efforts, the content of the IT budget raises the barrier of a relatively high level of operational costs comparing 
to the development costs. The IT function size is identified using the number of employees in the IT division. About the maturity of IT, prominent issues involve the knowledge of the IT manager on business objectives and the involvement of the top management in areas of planning and IT integration and strategy. Maturity in IT is not the same as the investment level in IT and a better way of measuring would be through IT capability in the company [15]. Thus, this study used IT maturity as a dimension of IT instead of investment in IT.

\subsection{Overview of literature on Effective IT governance}

ITG leads to improvement in the performance of IT and this, in turn, leads to improvement in the performance of the company. The study by [16] introduced a complete set of advantages aimed at companies based on the various dimensions of investments in IT. Since achieving the objectives causes an increase in value creation, which in turn shows the achievement of effective ITG, this causal association ascertains the usage of the parts of the objectives stated in survey questions that assessed the efficacy of ITG. [15] ITG can be applied under an integrated structure, process, and related tools. The structure of ITG includes the formal or structural devices and the mechanisms connected to enabling a horizontal relationship between IT and business decisions and functions (steering committees). The processes of ITG describe the formalized and institutionalized strategic decision making in IT or the processes of IT monitoring (such as the balanced scorecard).

\subsection{Overview of literature on Organization Performance}

A review of positions in the organization shows that they will perform successfully when allowed to react to the customers' demands in the environment [17] Point out the BSC is a strategic technique for the management to communicate and evaluate the achievement of the organization regarding mission and strategy. [18], the view that the BSC reveals the firm's shared vision. The balanced scorecard is among the most critical techniques for measuring as it can include the financial and non-financial components in measuring firm performance. The BSC is categorized into four perspectives namely financial, customers, internal business processes, and learning and growth. This research is based on the four perspectives of the BSC to create a holistic view and understanding of an ITG framework that is effective and its effect on the performance of the firm. Using this approach, proper strategies, actions, and plans can be used to nurture and build a conductive environment to establish an effective ITG.

\section{Research methodology}

\subsection{Sampling and data collection}

A quantitative study through a questionnaire survey has done for this research. The companies were randomly selected from the companies listing within the (FMM) and (directory of SME). The data collected from manufacturing organizations in Malaysia. Samples are selected from seven states (Selangor, Penang, Johor, Sarawak and Negeri Sembilan, Melaka, Pahang) of Malaysia because heavily populated and rather various manufacturing industry to let the results be generalized to a larger population. To reach the preferred sample size of 357 questionnaires were sent to 1037 companies, out of 1037 questionnaires there were 656 nonresponses, 371 responded, and 357 were usable. The response rate in this study is $35.7 \%$. [19] recommended the desired sample size of 200 as minimum and 400 as the maximum for Structural Equation Modeling (SEM) studies. This study used a simple random sampling, so every element in the population has the same chance of being selected [20]. Managers from the manufacturing companies were the participants in the survey exercise since this group did provide accurate answers to the research subjects of IT governance Initiative, effective ITG, and organizational performance practices as operationalized in the questionnaire. SEM test is an appropriate tool for this study; SEM permits both confirmatory and exploratory models forming. In other words, SEM is suitable for testing a theory testing and also developing it [21]. Based on a theoretical perspective, and because this research is confirmatory, it is rational to use the AMOS.

\subsection{Measures and questionnaire development}

There are 82 items in this research and the fivepoint Likert scale has used. The investigation of the data and information about the number of factors was done by an exploratory factor. Therefore, confirmatory factor analysis (CFA) was conducted 
using Covariance-based structural equation modeling (CB-SEM) with the software tools of AMOS 20 where the maximum likelihood estimation approach was applied. SEM test is an appropriate tool for this study; SEM permits both confirmatory and exploratory models forming. In the first CFA model (Table 1), it was apparent that model fit indices such as goodness-of-fit index $(\mathrm{GFI})=0.861,(\mathrm{AGFI})=0.885$ were very poor (acceptable threshold. 0.90), and (RMR) $=0.078$ (threshold < 0.05).The items X9, X10, G3, C8, and P3, were deleted and the model was reassessed. Therefore, after five items were dropped CFA was run again. Thus, it shows better fit for few measures in model 2, e.g. GFI $=0.908$, (RMSEA) $=0.058$; however, p-value $(0.000)$ still remained unacceptable. As seen from Table 1, the $\chi^{2}$ value of 1338.235 for the model has dropped to 972.491, while the values of GFI, AGFI, CFI, and TLI have appreciated to $0.908,0.914,0.953$, and 0.936 , respectively. In Model 3 therefore the goodness-offit indices of the revised model construct show a better fit (Table 1). P-value $=0.000, \mathrm{GFI}=0.961$, AGFI $=0.977, \mathrm{CFI}=0.951$ and $\mathrm{RMSEA}=0.039$ ).

Table1. Goodness-of-fit Indices for the Structural Model

\begin{tabular}{|l|l|l|l|l|l|l|l|}
\hline Models & CMIN & $\mathrm{p}$ & GFI & TLI & CFI & NFI & RMSEA \\
\hline Mode 1 & 1338.235 & 0.000 & 0.861 & 0.903 & 0.915 & 0.849 & 0.078 \\
\hline Mode12 & 972.491 & 0.000 & 0.908 & 0.936 & 0.953 & 0.927 & 0.058 \\
\hline Mode13 & 721.795 & 0.000 & 0.961 & 0.944 & 0.951 & 0.927 & 0.039 \\
\hline
\end{tabular}

From Table 2, it is obvious that the composite reliability and Cronbach values for all the constructs are well above the conventional threshold value of 0.70. Based on [19], the acceptable value for Cronbach's alpha is 0.7 ; while the values of AVE are well above 0.40 confirming reliability. According to [22], the high values of each of the factor loadings confirm the Convergent validity. Figures in Table 2 also show the recommended standard value of AVE of the variables confirming their discriminant validity.

Table 3.Reliability and Validity Measures 


\begin{tabular}{|c|c|c|c|c|c|c|c|c|c|c|c|}
\hline Constructs & $\begin{array}{l}\text { Compo } \\
\text { site } \\
\text { Reliabi } \\
\text { lity } \\
\end{array}$ & AVEa & $\begin{array}{l}\text { Cronba } \\
\text { ch's } \\
\alpha\end{array}$ & I & $\mathrm{C}$ & $\mathrm{D}$ & $\mathrm{O}$ & $\mathrm{X}$ & $\mathrm{F}$ & G & $\mathrm{P}$ \\
\hline $\begin{array}{c}\text { Involvement of } \\
\text { senior } \\
\text { Management }\end{array}$ & 0.834 & 0.425 & 0.794 & $(0.42)$ & & & & & & & \\
\hline $\begin{array}{c}\text { Corporate } \\
\text { communication } \\
\text { System }\end{array}$ & 0.797 & 0.421 & 0.765 & 0.057 & $(0.42)$ & & & & & & \\
\hline $\begin{array}{l}\text { Organizational } \\
\text { Demographics }\end{array}$ & 0.889 & 0.534 & 0.896 & 0.039 & 0.073 & $(0.534)$ & & & & & \\
\hline $\begin{array}{l}\text { Organizational } \\
\text { Culture }\end{array}$ & 0.874 & 0.402 & 0.837 & 0.024 & 0.044 & 0.28 & $(0.40)$ & & & & \\
\hline $\begin{array}{c}\text { External } \\
\text { Environment } \\
\text { Characteristic }\end{array}$ & 0.925 & 0.580 & 0.898 & 0.040 & 0.069 & 0.046 & 0.029 & $(0.50)$ & & & \\
\hline $\begin{array}{l}\text { IT Function } \\
\text { Characteristics }\end{array}$ & 0.912 & 0.511 & 0.736 & 0.038 & 0.069 & 0.045 & 0.030 & 0.047 & $(0.51)$ & & \\
\hline $\begin{array}{l}\text { Effective IT } \\
\text { governance }\end{array}$ & 0.878 & 0.520 & 0.901 & 0.040 & 0.067 & 0.063 & 0.029 & 0.046 & 0.045 & $(0.520)$ & \\
\hline $\begin{array}{l}\text { Organizational } \\
\text { performance }\end{array}$ & 0.907 & 0.498 & 0.812 & 0.028 & 0.047 & 0.032 & 0.21 & 0.033 & 0.033 & 0.032 & $(0.498)$ \\
\hline
\end{tabular}

\subsection{Hypotheses Testing}

To assess the mediating path the bootstrapping option in AMOS was selected.

[H1a]: There is a significant relationship between the involvement of senior management and effective IT governance.

[H1b]: There is a significant relationship between the involvement of senior management and organization performance.

[H1c]. Effective IT governance mediates the relationship between the involvement of senior management and organization performance.

An examination of the structural parameters in Table 3 reviewed that involvement of senior management $(\beta=0.314, z=2.962, p=0.006)$ has a significant influence on effective IT governance. However involvement of senior management $(\beta=$ $0.123, z=1.337, p=0.178$ ) is found to have no significance impact on organization performance. Similarly, Effective IT governance $(\beta=0.247, z=$ $3.127, p=0.019$ ) is found to have mediating effect between involvement of senior management and organization performance. To have a significant mediating effect, require that the $\mathrm{z}$-value to be $>$ absolute value of 1.96 and the $p$-value is $<0.05$. As a

result, Hypothesis H1a and H1c are accepted while Hypotheses $\mathrm{H} 1 \mathrm{~b}$ is rejected.
[H2a]: There is a significant relationship between the corporate communication system and effective IT governance.

[H2b]: There is a significant relationship between the corporate communication system and organization performance.

[H2c]: Effective IT governance mediates the relationship between the corporate communication system and organization performance.

The result shows that corporate communication system $(\beta=0.281, z=1.653, p=0.233>0.05)$ is not significant to effective IT governance. In this instance, Effective IT governance $(\beta=0.343, z=$ 2.157, $p=0.006>0.05$ ) is found to be a full mediator for corporate communication system in relation to organization performance. However, there is a significant relationship between corporate communication system $(\beta=0.261, z=3.107, p=$ $0.041<0.10)$ and organization performance. Hence, hypotheses $\mathrm{H} 2 \mathrm{~b}$ and $\mathrm{H} 2 \mathrm{c}$ are supported and $\mathrm{H} 2 \mathrm{a}$ is not supported.

[H3a]: There is a significant relationship between organizational demographics and effective IT governance.

[H3b]: There is a significant relationship between organizational demographics and organization performance.

[H3c]: Effective IT governance mediates the relationship between organizational demographics and organization performance. 
The research outcomes showed that organizational demographics $(\beta=0.503, z=3.619, p=0.000)$ was significantly related to effective IT governance, supporting hypothesis H3a. Similarly, organizational demographics $(\beta=0.202, z=1.530$, $p=0.127$ ) had no significant influence on organization performance, not supporting hypothesis H3b. Finally, effective IT governance $(\beta$ $=0.386, z=3.386, p=0.036)$ was found to have a full mediating effect on the association between organizational demographics and organization performance, supporting hypothesis $\mathrm{H} 3 \mathrm{c}$. As a result hypotheses $\mathrm{H} 3 \mathrm{a}, \mathrm{H} 3 \mathrm{c}$ have accepted accordingly, and $\mathrm{H} 3 \mathrm{~b}$ is rejected.

[H4a]: There is a significant relationship between organizational culture and effective IT governance.

[H4b]: There is a significant relationship between organizational culture and organization performance.

[H4c]: Effective IT governance mediates the relationship between organizational culture and organization performance.

For the three hypotheses about organizational culture ( $\mathrm{H} 4 \mathrm{a}, \mathrm{H} 4 \mathrm{~b}$, and $\mathrm{H} 4 \mathrm{c})$, an examination of the structural parameters shows that all relationships are as hypothesized. Organizational culture $(\beta=0.149, z$ $=1.096, p=0.027)$ is positively related to effective IT governance, providing evidence to support hypothesis H4a. However, contrary to hypothesis $\mathrm{H} 4 \mathrm{~b}$, organizational culture $(\beta=0.131, z=0.814, p$ $=0.064)$ is significant to organization performance. Hypothesis $\mathrm{H} 4 \mathrm{c}$ is statistically supported by the result of the mediation test, in which effective IT governance $(\beta=0.109, z=0.736, p=0.014)$ is a full mediator of the effect of organizational culture and organization performance.

[H5a]: There is a significant relationship between external environment characteristics and effective IT governance.

[H5b]: There is a significant relationship between external environment characteristics and organization performance.

[H5c]: Effective IT governance mediates the relationship between external environment characteristics and organization performance.

In this case external environment characteristic $(\beta=$ $0.245, z=3.141, p=0.051$ ) was tested to show significant influence on effective IT governance confirming H5a. External environment characteristic $(\beta=0.084, z=1.105, p=0.233)$ was not confirm to demonstrate significant impact on organization performance, not supporting hypothesis H5b. Effective IT governance $(\beta=0.102$, $z=2.267, p=0.009$ ) was found to have a full mediator role between external environment characteristic and organization performance and hence $\mathrm{H} 5 \mathrm{c}$ was supported. As a whole, hypotheses $\mathrm{H} 5 \mathrm{a}, \mathrm{H} 5 \mathrm{c}$ are accepted and $\mathrm{H} 5 \mathrm{~b}$ is rejected.

[H6a]: There is a significant relationship between IT function characteristics and effective IT governance.

[H6b]: There is a significant relationship between IT function characteristics and organization performance.

[H6c]: Effective IT governance mediates the relationship between external IT function characteristics and organization performance.

The outcome of analysis supported the hypothesized relationship between IT function characteristics and effective IT governance $(\beta=0.163 ; \mathrm{z}=2.173 ; \mathrm{p}=$ $0.007)$. Also IT function characteristics $(\beta=0.283$, $\mathrm{z}$ $=2.504, p=0.034$ ) have significant impact on organization performance. Effective IT governance $(\beta=0.213, z=2.393, p=0.000)$ was found to have a full mediator between the relationship IT function characteristics and organization performance.

[H7]: There is a significant relationship between effective IT governance and organization performance.

The research outcomes showed that effective IT governance $(\beta=0.397, z=2.738, p=0.000)$ was associated significantly with organization performance and hence Hypothesis $\mathrm{H} 7$ was accepted. This also implied that greater effort ineffective IT governance would result in a higher level of performance a company can achieve.

\section{Table4. AMOS Output for Hypotheses Testing}

\section{Conclusions}




\begin{tabular}{|c|c|c|c|c|c|c|}
\hline $\mathrm{H}$ & Paths & $\begin{array}{l}\text { Unstandar } \\
\text { dized }\end{array}$ & $\begin{array}{l}\text { Standar } \\
\mathrm{d} \\
\text { Errors }\end{array}$ & $\begin{array}{l}\text { Critical } \\
\text { Ratios }\end{array}$ & P-value & Results \\
\hline $\mathrm{H} 1 \mathrm{a}$ & $I \rightarrow G$ & 0.314 & 0.106 & 2.962 & $0.006^{* *}$ & Supported \\
\hline $\mathrm{H} 1 \mathrm{~b}$ & $\mathrm{I} \rightarrow \mathrm{P}$ & 0.123 & 0.092 & 1.337 & 0.178 & $\begin{array}{c}\text { Not } \\
\text { Supported }\end{array}$ \\
\hline $\mathrm{H} 1 \mathrm{c}$ & $\begin{array}{l}\mathrm{I} \rightarrow \\
\mathrm{G} \rightarrow \mathrm{P}\end{array}$ & 0.247 & 0.079 & 3.127 & $0.019 *$ & Supported \\
\hline $\mathrm{H} 2 \mathrm{a}$ & $\mathrm{C} \rightarrow \mathrm{G}$ & 0.281 & 0.170 & 1.653 & 0.233 & $\begin{array}{c}\text { Not } \\
\text { Supported }\end{array}$ \\
\hline $\mathrm{H} 2 \mathrm{~b}$ & $\mathrm{C} \rightarrow \mathrm{P}$ & 0.261 & 0.084 & 3.107 & $0.041^{*}$ & Supported \\
\hline $\mathrm{H} 2 \mathrm{c}$ & $\begin{array}{c}\mathrm{C} \\
\rightarrow \mathrm{G} \rightarrow \\
\mathrm{P}\end{array}$ & 0.343 & 0.159 & 2.157 & $0.006^{* *}$ & Supported \\
\hline $\mathrm{H} 3 \mathrm{a}$ & $\mathrm{D} \rightarrow \mathrm{G}$ & 0.503 & 0.139 & 3.619 & $\begin{array}{c}0.000 * * \\
*\end{array}$ & Supported \\
\hline $\mathrm{H} 3 \mathrm{~b}$ & $\mathrm{D} \rightarrow \mathrm{P}$ & 0.202 & 0.132 & 1.530 & 0.127 & $\begin{array}{c}\text { Not } \\
\text { Supported }\end{array}$ \\
\hline $\mathrm{H} 3 \mathrm{c}$ & $\begin{array}{l}\mathrm{D} \rightarrow \\
\mathrm{G} \rightarrow \mathrm{P}\end{array}$ & 0.386 & 0.114 & 3.386 & $0.036^{*}$ & Supported \\
\hline $\mathrm{H} 4 \mathrm{a}$ & $\mathrm{O} \rightarrow \mathrm{G}$ & 0.149 & 0.136 & 1.096 & $0.027^{*}$ & Supported \\
\hline $\mathrm{H} 4 \mathrm{~b}$ & $\mathrm{O} \rightarrow \mathrm{P}$ & 0.131 & 0.161 & 0.814 & $0.064 \dagger$ & Supported \\
\hline $\mathrm{H} 4 \mathrm{c}$ & $\begin{array}{l}\mathrm{O} \rightarrow \\
\mathrm{G} \rightarrow \mathrm{P}\end{array}$ & 0.109 & 0.148 & 0.736 & 0.014* & Supported \\
\hline $\mathrm{H} 5 \mathrm{a}$ & $X \rightarrow G$ & 0.245 & 0.078 & 3.141 & $0.051 \uparrow$ & Supported \\
\hline $\mathrm{H} 5 \mathrm{~b}$ & $X \rightarrow P$ & 0.084 & 0.076 & 1.105 & 0.233 & $\begin{array}{c}\text { Not } \\
\text { Supported }\end{array}$ \\
\hline $\mathrm{H} 5 \mathrm{c}$ & $\begin{array}{l}X \rightarrow \\
G \rightarrow P\end{array}$ & 0.102 & 0.045 & 2.267 & $0.009^{* *}$ & Supported \\
\hline H6a & $\mathrm{F} \rightarrow \mathrm{G}$ & 0.163 & 0.075 & 2.173 & $0.007 * *$ & Supported \\
\hline $\mathrm{H} 6 \mathrm{~b}$ & $\mathrm{~F} \rightarrow \mathrm{P}$ & 0.283 & 0.113 & 2.504 & $0.034 *$ & Supported \\
\hline H6c & $\begin{array}{c}\mathrm{F} \rightarrow \mathrm{G} \\
\rightarrow \mathrm{P}\end{array}$ & 0.213 & 0.089 & 2.393 & $\begin{array}{c}0.000^{* *} \\
*\end{array}$ & Supported \\
\hline $\mathrm{H} 7$ & $\mathrm{G} \rightarrow \mathrm{P}$ & 0.397 & 0.145 & 2.738 & $\begin{array}{c}0.000^{* *} \\
*\end{array}$ & Supported \\
\hline
\end{tabular}

In conclusion, this research has concentrated on the factors that effective ITG and organization performance in manufacturing companies in Malaysia. Due to the importance of IT governance in Malaysia, this study can aid Managers and researchers to promote their knowledge about the importance of ITG and how it can benefit organization performance. Based on the literature, by considering both IT governance initiatives and effective ITG and their impact on manufacturing companies, effective ITG could enhance organization performance. Indeed, the findings provided useful information related to ITG that enlightened companies to their Productivity and performance, and assists them to survive in the hypercompetitive world.

\section{Contributions of the Study}

\subsection{Theoretical Contributions}

\section{Resource-based View Theory}

Recently, the Resource-based View (RBV) theory attracts more attention in IT value research, as it serves as a theoretical framework for the identification of IT resources impacting firm performance. Although numerous empirical studies applying the RBV can be found, systematic research structuring the obtained knowledge is hardly available. Therefore, this research conducts an evidence-based literature review to structure and consolidate empirical evidence from studies using the RBV as a theoretical foundation. This study illustrated how ITG can be distinguished and classified by considering their operationalization. With the means of a research map, this research illustrated the findings and their evidence pointing out contradictory results of how ITG initiatives affect the IT Effective ITG in terms of the competitive advantage. This study discussed some direct effects of effective ITG on organizational performance as well as research gaps. ITG is a concept that allows achieving above-average returns of corporate investments through encouraging a desirable behavior with IT [21]. With yearly IT costs exceeding $\$ 1$ billion in large multinational corporations and being accountable for up to $15 \%$ of the turnover, the impact of ITG on organizational performance is indisputable. Today, ITG is a key enabler and success factor for organizational performance [15].

This study offers a model with theoretical linkages for understanding the effectiveness of a firm's IT governance initiatives. Although prior have identified the IT governance arrangements that may work best, measurement of the effectiveness of the arrangements has been effective. One of the significant contributions of this research is the introduction of IT governance initiatives on the effectiveness of ITG. These capabilities have strong backing as a source of value from a resourceoriented theoretical lens. Respectively, the application of the resource-based theory (RBV) provides a more robust explanation of determinants of measures of a firm's IT governance initiatives. 
This study used RBV to evaluating IT governance initiatives' effectiveness to how they may contribute to building effective ITG and increasing the performance in organizations [22].

\subsection{Practical Implications}

ITG has gained more importance in recent years in Malaysia, mainly due to the different trends in developments in IT. Due to the country's rapid development and the global development in the IT sector, the ITG in Malaysia has also seen a growing interest. In Malaysia, the IT sector has been growing at a rapid pace. In this regard, this research suggested some practical insights to the management of the organization in effecting ITG and increases the performance of the organization. Also, this study will encourage manufacturing industries to adopt ITG to build the right organizational performance in the market place.

\section{Limitations and Future Research}

Data was collected from production institutions covering, both MNCs and SMEs in Malaysia. The justification for selecting the cross-sectional style was to acquire enough sample size for analyses. Because the device of evaluation in the analysis was organizations instead of individuals, the inclination is normally that the sample size was likely to be little, especially, therefore, when the questionnaires had been distributed to a making sector alone. This research ought to be extended due to the accessible and different sample sizes. Additional analysis in replicating this research can be carried out in an industry-specific setting, such as service. In search of far more generalized research, upcoming research is encouraged to research this model in various other industries and growing countries. The results of the studies can offer empirical support and facilitate the acceptability of the model.

\section{References:}

[1] Teo, W.L., Manaf, A.A., Choong, P.L.F., Perceived effectiveness of information technology governance initiatives among IT practitioners". International Journal of Engineering Business Management. 2013, Vol. 5 No,1, pp.1-9.

[2] Ali, S and Green, P, Effective information technology (IT) governance mechanisms: An IT outsourcing perspective. Information Systems Frontiers. 2012, Vol, 14 No, 2, pp.179-193.

[3] De Haes, S. Van Grembergen, W. Debreceny, R.S., COBIT 5 and Enterprise Governance of
Information Technology: Building Blocks and Research Opportunities. Journal of Information Systems. 2013, Vol, 27No,1, pp.307-324.

[4] Ilmudeen, A., A Review on the Relationship Variables of IT Governance and Organization Performance. International Journal of Innovative Research and Practices. 2014, Vol, 2 No, 8.

[5] Lunardi, G.L. Becker, J. L. Macada, A.G. Dolci, P.C., The impact of adopting IT governance on financial performance: An empirical analysis among Brazilian firms. International Journal of Accounting Information Systems. 2014, Vol, 15 No,1, pp.66-81.

[6] Tan, K. S. Teo, W.L. Lai, K. P.,The applicability of information technology governance in the Malaysian SMEs. Journal of Innovation Management in Small and Medium Enterprises. 2011, pp.1-10.

[7] Ismail, N. A. and King, M., Factors influencing the alignment of accounting information systems in small and medium-sized Malaysian manufacturing firms. Journal of Information Systems and Small Business. 2014, Vol, 1 No,12, pp.1-20.

[8] Abdollahbeigi B. and Salehi, F., The critical factors of IT governance and its impact on organizational performance in the Malaysian manufacturing industry. Serbian Journal of Management. 2020, Vol, 15 No,1, pp.81-99.

[9] Mugwe, C., Determinants for Effective Information Technology Outsourcing: A Case of International Business Machines Corporation Kenya,2014.

[10] Mohamed, N. and Singh, J.K., A conceptual framework for information technology governance effectiveness in private organizations. Information Management \& Computer Security. 2012, 20(2), 88-106.

[11] Salehi, F, Jayashree, S. Malarvizhi, C.A. Abdollahbeigi, B., The effect of involvement of senior management in it, strategy committee, organizational demographics through effective IT Governance on Organization Performance". International Information Institute (Tokyo). Information. 2014, Vol, 21 No, 4, pp.12651272.

[12] Subriadi, A.P. Hadiwidjojo, D. Rahayu, M. Sarno, R.., Firm age, Firm Size and Information Technology intensity industry factors in influencing Information Technology contribution to improving performance. Journal 
of Theoretical and Applied Information Technology. 2013, Vol, 55 No, 1, pp. 126-136.

[13] Abdollahbeigi, B and Salehi, F., the Effect of External Environment Characteristics on Effective IT Governance through Organizational Performance. The Journal of Technology Management and Technopreneurship (JTMT). 2019, Vol.7 No., pp. 19-28.

[14] Salehi, F. Jayashree, S. Malarvizhi, C.A. Abdollahbeigi, B., The Influence of External Environment Characteristics on Effective IT Governance and Organizational Performance. International Social Science Conference \& Innovation Challenge - Law and Business: A Dynamic Equilibrium. Malaysia.2018.

[15] DeHaes, S. and Van Grembergen, W., Analyzing the impact of enterprise governance of IT practices on business performance. International Journal on IT/Business Alignment and Governance, 2010, Vol. 1 No. 1, pp. 14-3.

[16] Dolci, P.C. and Maçada, A.C.G., The dimensions of IT portfolio management (ITPM): an analysis involving IT managers in Brazilian companies. JISTEM Journal of Information Systems and Technology Management. São Paulo, 2013, pp. 8- 2.

[17] Kaplan, R. S. and Norton, D.P., "Balanced Scorecard- Measures That Drive Performance". Havard Business Review. January February, 1992, pp.70-79.

[18] Atarere, O.L. and Oroka, O.V., Roles of Balanced Scorecard in Improving the Performance of Microfinance Banks in Nigerian Economy. International Journal of Research and Development. 2012, pp. 280-287.

[19] Hair, J.F. Black, W.C. Babin, B.J. Anderson, R.E., Multivariate Data Analysis: A Global Perspective. 7th Edition, Pearson Education. Upper Saddle River.2010.

[20] Sekaran, U., Research Methods for Business: A Skill-Building Approach. 4th Edition. John Wiley \& Sons, New York. 2003.

[21] Baron, R.M. and Kenny, D., the ModeratorMediator Variable Distinction in Social Psychological Research: Conceptual, Strategic, and Statistical Considerations. Journal of Personality and Social Psychology. 1986,Vol. 51, pp.1173-1182.

[22] Chin W.W., How to Write Up and Report PLS Analyses". In: Esposito Vinzi V., Chin W., Henseler J., Wang H. (eds) Handbook of Partial Least Squares. Springer Handbooks of Computational Statistics. Springer, Berlin,2010.
Heidelberg. https://doi.org/10.1007/978-3-54032827-8_29.

[23] Abdollahbeigi, B and Salehi, F., The Effect of Corporate Communication System and Involvement of Senior Management on Effective IT Governance and Organizational Performance. Journal of Applied Structural Equation Modeling. 2020, Vol, 4 No, 1, pp. 6580.

\section{Creative Commons Attribution License 4.0 (Attribution 4.0 International, CC BY 4.0)}

This article is published under the terms of the Creative Commons Attribution License 4.0

https://creativecommons.org/licenses/by/4.0/deed.en_US 